\title{
ARTICLE
}

\section{Reversible adapting layer produces robust single-crystal electrocatalyst for oxygen evolution}

\author{
Ching-Wei Tung ${ }^{1, \star}$, Ying-Ya Hsu ${ }^{2, \star}$, Yen-Ping Shen ${ }^{1}$, Yixin Zheng ${ }^{1}$, Ting-Shan Chan ${ }^{3}$, Hwo-Shuenn Sheu ${ }^{3}$, \\ Yuan-Chung Cheng ${ }^{1} \&$ Hao Ming Chen ${ }^{1}$
}

Electrochemically converting water into oxygen/hydrogen gas is ideal for high-density renewable energy storage in which robust electrocatalysts for efficient oxygen evolution play crucial roles. To date, however, electrocatalysts with long-term stability have remained elusive. Here we report that single-crystal $\mathrm{Co}_{3} \mathrm{O}_{4}$ nanocube underlay with a thin $\mathrm{CoO}$ layer results in a high-performance and high-stability electrocatalyst in oxygen evolution reaction. An in situ X-ray diffraction method is developed to observe a strong correlation between the initialization of the oxygen evolution and the formation of active metal oxyhydroxide phase. The lattice of skin layer adapts to the structure of the active phase, which enables a reversible facile structural change that facilitates the chemical reactions without breaking the scaffold of the electrocatalysts. The single-crystal nanocube electrode exhibits stable, continuous oxygen evolution for $>1,000 \mathrm{~h}$. This robust stability is attributed to the complementary nature of defect-free single-crystal electrocatalyst and the reversible adapting layer.

\footnotetext{
${ }^{1}$ Department of Chemistry, National Taiwan University, Taipei 106, Taiwan. ${ }^{2}$ Program for Science and Technology of Accelerator Light Source, National Chiao Tung University, Hsinchu 300, Taiwan. ${ }^{3}$ National Synchrotron Radiation Research Center, Hsinchu 300, Taiwan. * These authors contributed equally to this work. Correspondence and requests for materials should be addressed to H.M.C. (email: haomingchen@ntu.edu.tw).
} 
G rowing concerns about global warming and increasing demands for energy have prompted the search for renewable energy sources and the development of improved energy storage options to replace fossil fuel technologies ${ }^{1-7}$. In many of the innovative approaches for addressing these challenges, photoelectrolyzing or electrolyzing water to produce oxygen and hydrogen gases is a highly scalable method for storing chemical fuels derived from renewable sources $^{8-10}$. Therefore, the development of abundant, robust and efficient catalysts for photoelectrochemical/electrochemical production of oxygen are crucial for the long-term viability of our community.

In recent years, various materials including simple oxides ${ }^{11-15}$, combinations of transition metal oxides ${ }^{16-20}$, phosphates ${ }^{21,22}$, oxyhydroxide 23,24 , perovskites ${ }^{10,25}$ and nanocomposite materials ${ }^{26-29}$ have been used to induce an oxygen evolution reaction (OER) in alkaline environment. Despite the interesting catalytic behaviours of existing materials, an inexpensive and reliable electrocatalyst that does not develop defects to hinder charge transfer across the electrolyte/catalyst interface has yet to be achieved. Recent reports of highly economic and efficient electrochemical catalysts have significantly advanced this technology ${ }^{14}$, however the largest challenge concerning the reliability of the catalyst remains yet unconquered. A major reason for the slow progress of reliable catalysts in the OER is that the electrocatalyst bears most of the charge carriers during the harsh oxidization process because the OER normally occurs under a high anodic potential. A highly stable electrocatalyst has to transfer charge carriers effectively to the OER electrocatalyst/ electrolyte interface yet retain a sufficient amount of oxidized species during anodization. To shed light on such complex surface reactions, we need a tool that allows in situ observation of the active phase of metal centres under anodization and a novel strategy to protect electrocatalysts under such harsh conditions in order to achieve reliable catalysts for OER.

The oxygen evolution activity of electrocatalysts depends strongly on corresponding surface structures and the adsorption energies of intermediates on metal oxide surfaces ${ }^{30,31}$. Generally speaking, surface structure can affect the activity of electrocatalysts and surface states can be further altered by introducing foreign elements, which leads to considerable decreases in overpotential and therefore increases in activity during the OER. In practical conditions, the reactions of OER are only involved within a several nanometre region of the catalyst surface, and in situ studies within this limited region are essential and extremely challenging. Recently, in situ Raman spectroscopy has been conducted to achieve this goal to reveal the intermediates through surface binding of OER reactants ${ }^{11}$. Moreover, Zhang et al. ${ }^{32}$ identified the surface bonding formation and relevant intermediates through time-resolved rapid-scan Fourier transform infrared spectroscopy, in which a surface superoxide species was revealed in a fast reaction cycle of OER. However, for designing efficient OER catalysts, in situ study for structure and crystallinity at the atomic level of the metal centres in the catalyst surface are vital and have yet to be achieved. The development of tools to study and investigate the surface of catalysts could provide a powerful means to elucidate fundamental processes in OER catalyst and eventually lead to a novel design principle.

Herein, we investigate single-crystal $\mathrm{Co}_{3} \mathrm{O}_{4}$ nanocubes with underlaying of uniform cobalt oxide (CoO) layers as OER electrocatalysts. The strategy is to incorporate a surface layer well adapted to the active phases of the catalytic metal centres to enhance the stability of the electrocatalysts. Furthermore, we develop an in situ grazing-angle X-ray diffraction method to track the atomic-scale structural changes on the surface of the electrode during OER in liquid conditions. This powerful technique reveals that the $\mathrm{CoO}$ layer can reversibly adapt to the harsh conditions of OER through reversible structural transformations, which results in a highly robust electrocatalyst. In addition, we choose $\mathrm{Co}_{3} \mathrm{O}_{4}$ because of its abundance, low cost, low electrical resistance, thermodynamic stability and moderate overpotential in neutral and alkaline conditions ${ }^{33}$. Using single-crystal nanocubes as OER electrocatalysts provide strong mechanical strength, minimal structural disorder and defect-free substrates. The structural defects in materials normally turn into trap states that play a dominant role in limiting carrier transportation, and effective carrier transportation within the substance determines the overall efficiency of the devices ${ }^{34,35}$. Accordingly, the low trap density of the single-crystal defect-free nanostructure enhances its carrier dynamics and thereby improve the electronic properties of the materials. The $\mathrm{CoO}$ layer on the surface of the $\mathrm{Co}_{3} \mathrm{O}_{4}$ nanocubes forms a reversible adaption junction, enabling a facile structural transformation $^{18}$ for chemical reactions (for example, OER) and the formation of active phase without breaking the scaffold of the electrocatalysts (for example, $\mathrm{Co}_{3} \mathrm{O}_{4}$ nanocubes) to further reduce the overpotential.

\section{Results}

Structural characterization of $\mathrm{Co}_{3} \mathrm{O}_{4}-\mathrm{CoO}$ core-shell nanocube. The pristine $\mathrm{Co}_{3} \mathrm{O}_{4}$ nanocubes prepared by using a surfactantfree method, in which $\mathrm{Co}_{3} \mathrm{O}_{4}$ nanocubes was formed through a reaction of cobalt hydroxides and dissolved oxygen in an aqueous medium. Sequentially a thin $(\sim 1 \mathrm{~nm}) \mathrm{CoO}$ film was prepared on the single-crystal $\mathrm{Co}_{3} \mathrm{O}_{4}$ nanocube surface by using reducing agent (sodium borohydride) with an accurate control of $\mathrm{CoO}$ covering to form a $\mathrm{Co}_{3} \mathrm{O}_{4}-\mathrm{CoO}$ core-shell nanocube, with the average size of the $\mathrm{Co}_{3} \mathrm{O}_{4} @ \mathrm{CoO}$ single-crystal cubes (SCs) $<50 \mathrm{~nm}$ (Fig. 1a). A high-resolution transmission electron microscope (HRTEM) was employed to characterize the nanostructure of the core-shell cubes (Fig. 1b; Supplementary Fig. 1) and the selected area electron diffraction of the individual nanocube was characteristic of the single-crystal structure. A set of spots were indexed to the $\mathrm{Co}_{3} \mathrm{O}_{4}$ spinel structure along the [001] zone axis, and the boundary planes of the nanocube were $\{100\},\{010\}$ and $\{001\}$ (Fig. 1c). A thin, bright layer with a thickness of $\sim 1 \mathrm{~nm}$ was located on the surface of the $\mathrm{Co}_{3} \mathrm{O}_{4}$, indicating that $\mathrm{CoO}$ uniformly covered the entire surface of the $\mathrm{Co}_{3} \mathrm{O}_{4}$ nanocube. Corresponding spatial distributions of the compositional elements within the individual nanocube were obtained using a scanning transmission electron microscopeenergy-dispersive X-ray line scan through the entire nanocube (indicated in Fig. 1d), revealing that the core-shell nanocube comprised $\mathrm{Co}$ and $\mathrm{O}$, and the compositional profiles were symmetrical because of the uniform covering of cobalt oxide. The atomic lattice fringes identified in the HRTEM image was shown in Fig. 1e. It indicated that the nanocube was single crystalline, which was consistent with the result from selected area electron diffraction image. The lattice fringe of a representative nanocube with a $d$-spacing of $2.8 \AA$ could be assigned to the (220) plane of spinel $\mathrm{Co}_{3} \mathrm{O}_{4}$ (JCPDS file nos. 43-1003, $a=8.084 \AA$; Supplementary Fig. 2). It was worth noting that the bright outer layer exhibited a clear lattice fringe with a $d$-spacing of $2.1 \AA$, corresponding to the (200) plane of $\mathrm{CoO}$ (JCPDS file nos. $78-0431, a=4.2667 \AA$ ). To further characterize the thin cobalt oxide layer, electron energy-loss spectroscopy (EELS), a powerful technique for local structural analysis featuring nanometre spatial resolution, was performed. The $L_{3} / L_{2}$ line ratio for the Co- $L$ edge served as a fingerprint for the Co valence state ${ }^{36}$, and a $3.2 L_{3} / L_{2}$ line ratio for the Co EELS peaks was recorded at the middle of the core-shell nanocube as shown in Fig. 1f. This ratio was consistent 
a

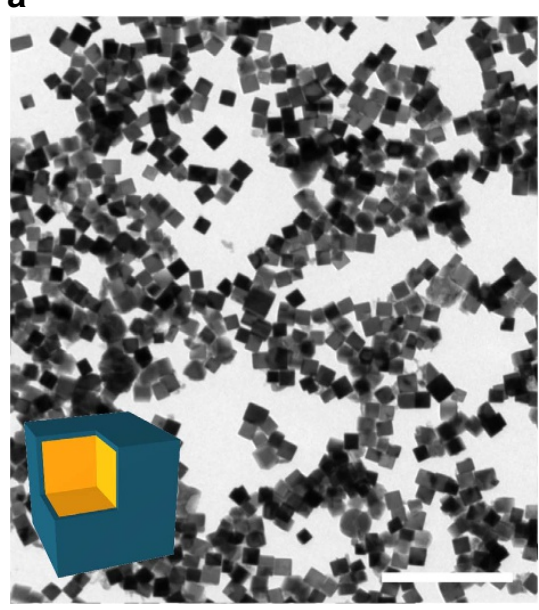

b

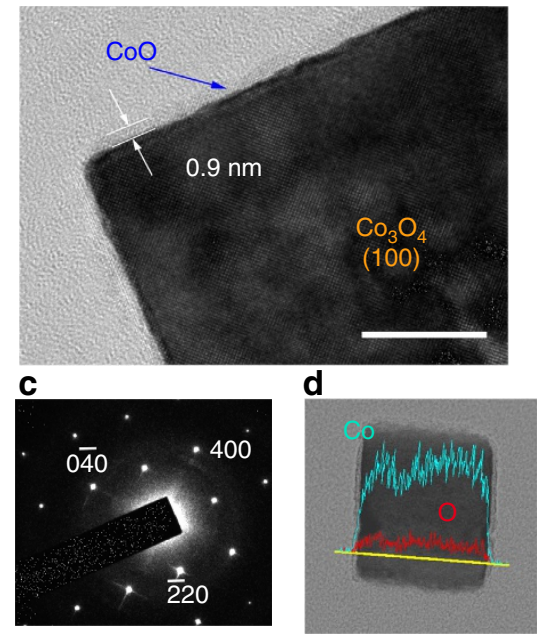

f

e
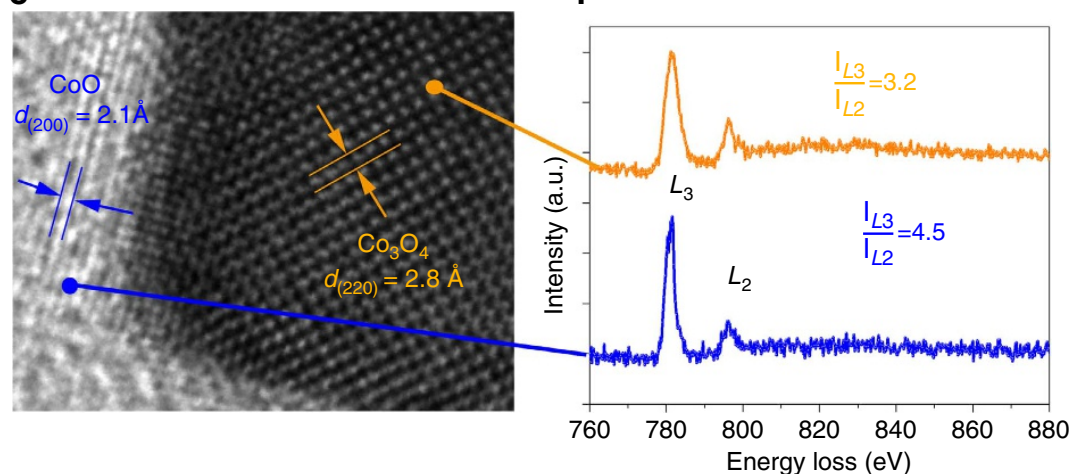

Figure 1 | Structural characterization of the $\mathbf{C O}_{3} \mathbf{O}_{\mathbf{4}} @ \mathbf{C o O}$ single-crystal nanocubes. (a,b) A typical transmission electron micrograph. Scale bar, $200 \mathrm{~nm}(\mathbf{a}) ; 10 \mathrm{~nm}$ (b). (c) Selected area electron diffraction pattern of an individual $\mathrm{Co}_{3} \mathrm{O}_{4} @ \mathrm{CoO}$ single-crystal nanocube. (d) The corresponding elemental line scan from the $\mathrm{Co}$ and $\mathrm{O}$ of an individual $\mathrm{Co}_{3} \mathrm{O}_{4} @ \mathrm{CoO}$ single-crystal nanocube. (e) HRTEM image of a $\mathrm{Co}_{3} \mathrm{O}_{4} @ \mathrm{CoO}_{0}$ single-crystal nanocube. The dark area is the $\mathrm{Co}_{3} \mathrm{O}_{4}$ and the light area is the $\mathrm{CoO}$. (f) Corresponding electron energy-loss spectrum of a $\mathrm{Co}_{3} \mathrm{O}_{4} @ \mathrm{CoO} \mathrm{SC}$ nanocube. The upper spectrum was recorded at the dark area of $\mathbf{e}$ and the lower spectrum was recorded at the light region of $\mathbf{e}$.

with the value regarding $\mathrm{Co}_{3} \mathrm{O}_{4}$ (II + III; upper part of Fig. 1f). In the outermost region (lower part), the $L_{3} / L_{2}$ line ratio for the Co peaks was $\sim 4.5$, which is close to the expected value for $\mathrm{CoO}$ (II). Consequently, a single-crystal $\mathrm{Co}_{3} \mathrm{O}_{4}$ nanocube with $\mathrm{CoO}$ $(\sim 1 \mathrm{~nm})$ uniformly covering the surface was characterized, in which nanocube catalysts exposed the energetically preferred (001) surfaces of OER to electrolyte ${ }^{32}$.

In situ X-ray spectroscopy studies in liquid environment. Since the catalytic performance is strongly dependent on the relevant surface state of electrocatalysts, it would be highly desirable if surface reactive structures could be monitored in liquid condition. In gas evolution situation, obtaining stable signals and monitoring the surface state of catalysts in liquid environment is an extremely difficult task. To achieve this aim, we customized a reaction cell and utilized the synchrotron radiation light source owing to the extremely high intensity and flux of the light source. An in situ grazing-angle X-ray diffraction approach in liquid environment can be achieved to determine the atomic structure of the catalysts surface in ambient condition (Fig. 2a), especially for gas evolution situation (high potential region). Figure $2 b$ depicts the current density as a function of applied voltage, and are colour coded together with diffracted intensities recorded using $12 \mathrm{keV}$ of synchrotron light. At the early stage (before $\mathrm{O}_{2}$ evolution), main reflexes were attributed to the fluorine-doped tin oxide substrate and the spinel-type $\mathrm{Co}_{3} \mathrm{O}_{4}$ phases. No $\mathrm{CoO}$ phase was observed, indicating that the $\mathrm{CoO}$ layer was too thin to diffract the light source (a few atomic layers). At a higher voltage, accompanying the formation of $\beta$-CoOOH (JCPDS file no. 140673) on the surface of electrode, the electrodes began oxygen gas evolution in both alkaline and neutral conditions. This suggested that the CoO layer was converted into more active phase with increasing applied potential. When the applied voltage was further increased, a new phase, $\alpha$-CoOOH (JCPDS file no. 26-0480) was observed. Both alkaline and neutral conditions demonstrated a similar phenomenon that OER was strongly correlative with the formation of metal oxyhydroxide. This was direct evidence for the formation of metal oxyhydroxide during higher oxygen gas evolution $\left(\sim 30 \mathrm{mAcm}^{-2}\right)$ in an in situ liquid environment. Notably, the CoO layer functioned as an adapting junction between electrolyte and catalyst to ease off the strain in the nanocrystal substrates when the active phases were formed. As shown in Fig. 2c, when applied potential was cycled between +2.0 and $+0.1 \mathrm{~V}$ (versus RHE; Reversible Hydrogen Electrode), the in situ X-ray diffraction approach showed that this junction layer could alter its structure reversibly between metal oxyhydroxide and amorphous phases. This observation revealed that this skin junction could reversibly adapt to the environment (applied potential) and condition change during catalyzing reaction, consequently protecting the underlay catalyst (for example, $\mathrm{Co}_{3} \mathrm{O}_{4}$ ) anodizing from applied bias. Moreover, we performed 
a
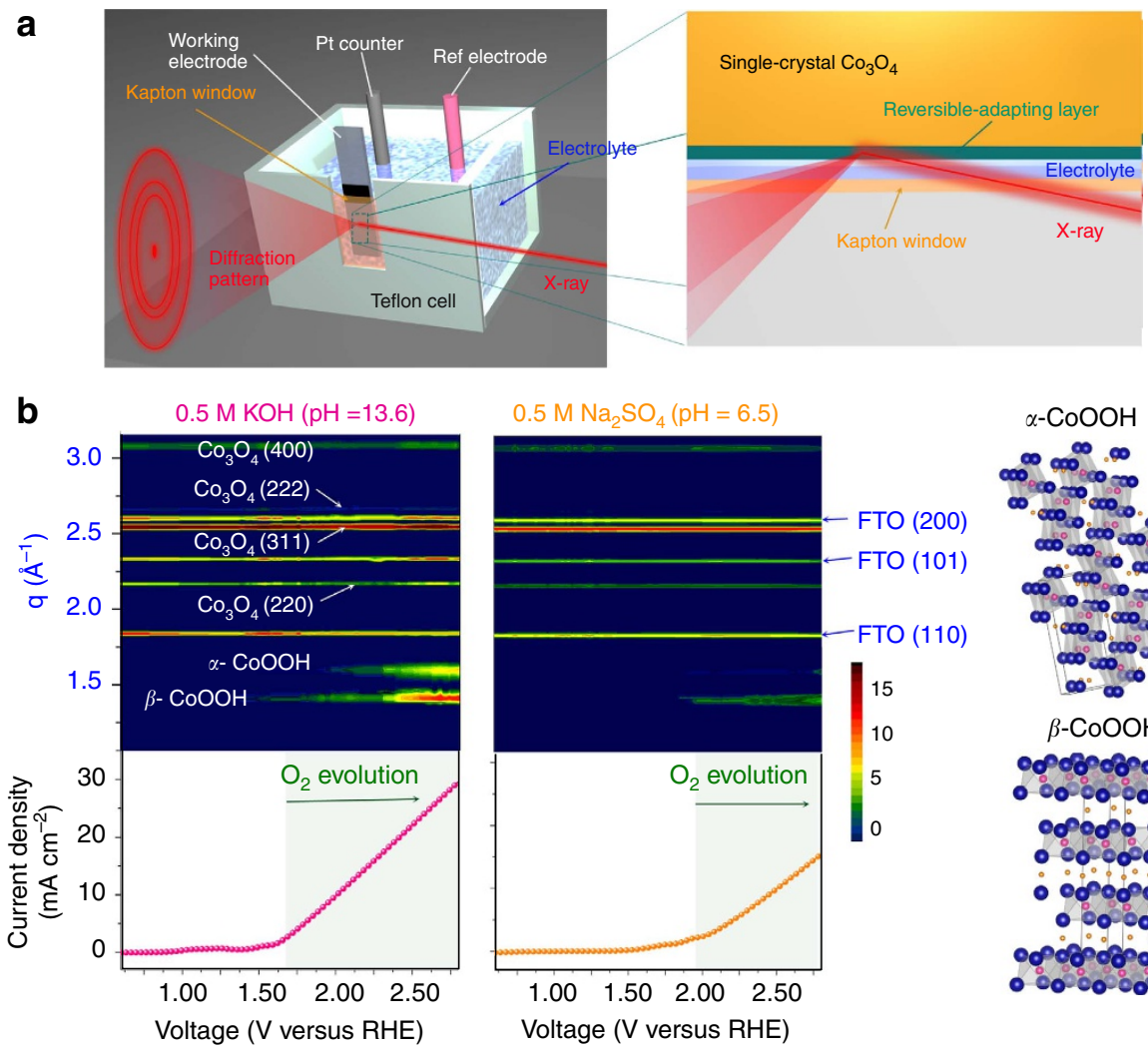

$\alpha-\mathrm{CoOOH}$
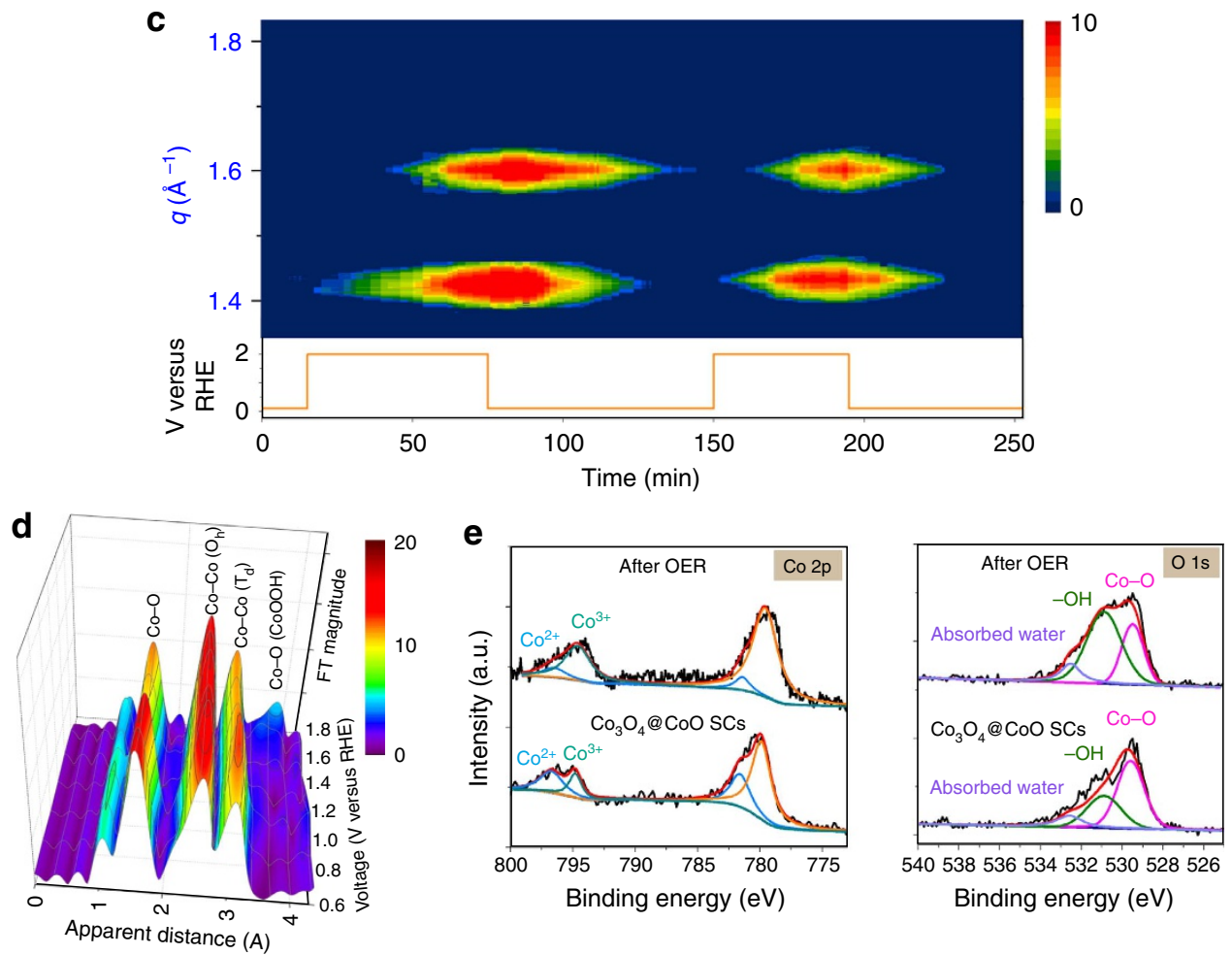

Figure 2 | In situ investigation of cobalt oxide SC catalysts during a water oxidation reaction in a liquid environment. (a) Schematic representation of the in situ grazing-angle X-ray diffraction apparatus applied to a liquid electrochemical cell. (b) Contour plots of in situ grazing-angle X-ray diffraction signals of a $\mathrm{Co}_{3} \mathrm{O}_{4} @ \mathrm{CoO} \mathrm{SC}$ in an aqueous solution containing $0.5 \mathrm{M} \mathrm{KOH}(\mathrm{pH}=13.6)$ and $0.5 \mathrm{M} \mathrm{Na}_{2} \mathrm{SO}_{4}(\mathrm{pH}=6.5)$. The images show the diffraction intensity (colour coded) as a function of voltage, and data collection was performed at the NSRRC synchrotron facility by using $12 \mathrm{keV}$ of energy. The lower curves show the measured current density in both cases. (c) Contour plots of in situ grazing-angle X-ray diffraction signals of a $\mathrm{Co}_{3} \mathrm{O}_{4} @ \mathrm{CoO} \mathrm{SC}$ in an alkaline aqueous solution under switching of voltage (between 2.0 and $0.1 \mathrm{~V}$ versus RHE), and data collection was performed at the synchrotron facility by using $10 \mathrm{keV}$ of energy to achieve better position distinguishability. (d) Voltage-dependence Fourier transform extended X-ray absorption fine structure spectra of $\mathrm{CO}_{3} \mathrm{O}_{4} @ \mathrm{CoO} S \mathrm{~S}$ in an alkaline aqueous solution containing $0.5 \mathrm{M} \mathrm{KOH}(\mathrm{pH}=13.6)$ and in an in situ liquid cell. (e) XPS $\mathrm{Co} 2 p$ and $\mathrm{O} 1 \mathrm{~s}$ core-level spectra of the $\mathrm{Co}_{3} \mathrm{O}_{4} @ \mathrm{CoO} \mathrm{SCs}$ before and after oxygen evolution reaction. 

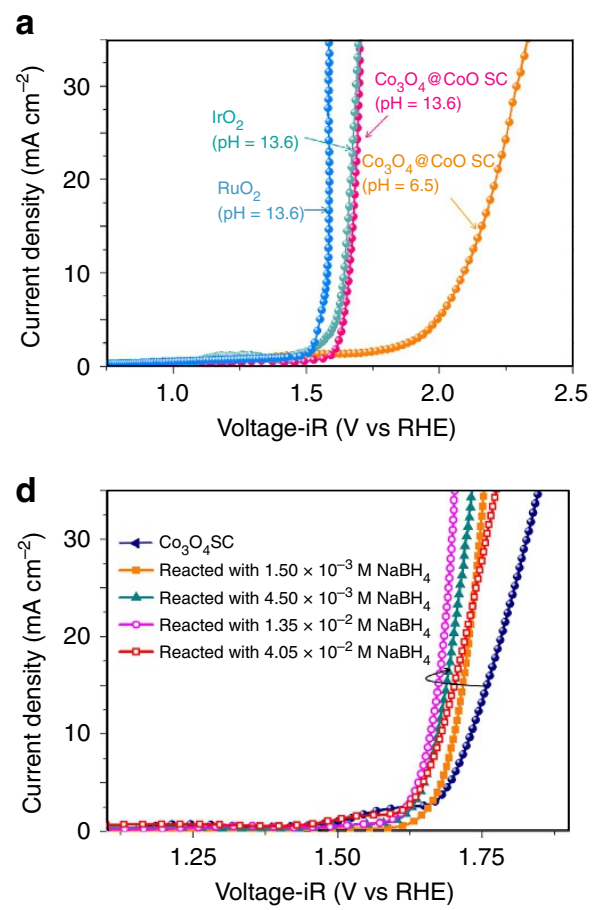

b

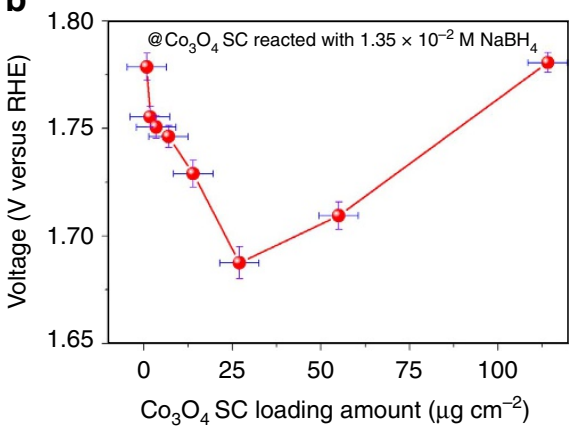

e

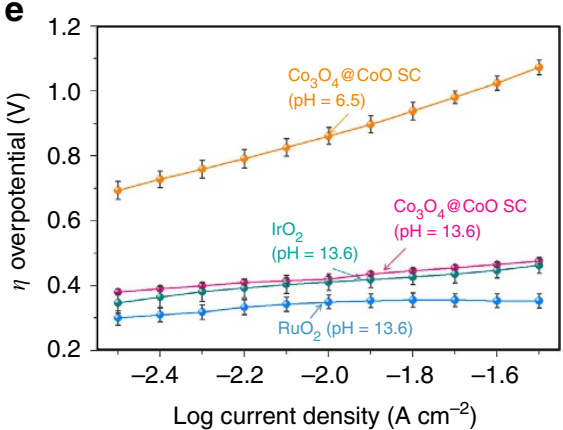

c

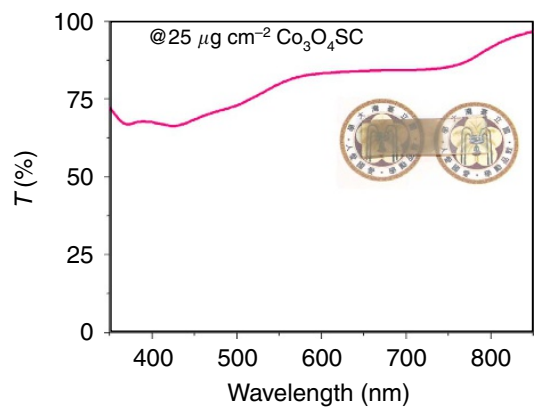

f

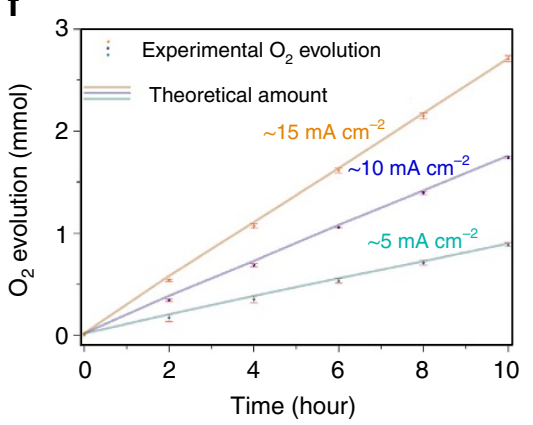

Figure 3 | Electrochemical characterization of $\mathbf{C O}_{3} \mathbf{O}_{\mathbf{4}} @ \mathbf{C o O}$ single-crystal nanocubes. (a) OER polarization curves of $\mathrm{Co}_{3} \mathrm{O}_{4} @ \mathrm{CoO}$ single-crystal nanocubes in alkaline ( $0.5 \mathrm{M} \mathrm{KOH} ; \mathrm{pH} \sim 13.6)$ and neutral $\left(0.5 \mathrm{M} \mathrm{Na}_{2} \mathrm{SO}_{4} ; \mathrm{pH} \sim 6.5\right)$ conditions, commercial RuO $\mathrm{O}_{2}$ catalysts $(0.5 \mathrm{M} \mathrm{KOH} ; \mathrm{pH} \sim 13.6)$, and $\mathrm{IrO}_{2}$ catalysts $(0.5 \mathrm{M} \mathrm{KOH} ; \mathrm{pH} \sim 13.6)$; the voltage was corrected according to $\mathrm{iR}$ loss from solution resistance. All measurements were performed using an identical catalyst amount $\left(25 \mu \mathrm{cm}^{-2}\right.$ ) and rotating disk electrode (RDE) voltammetry upon a glassy carbon (GC) disk. (b) Voltage (versus RHE@ $5 \mathrm{~mA} \mathrm{~cm}^{-2}$ ) as a function of the catalyst loading amount $\left(\mu \mathrm{g} \mathrm{cm}^{-2}\right)$, indicating that applying the optimized loading amount $\left(25 \mu \mathrm{cm} \mathrm{cm}^{-2}\right)$ facilitated achieving the optimal overpotential value for the OER. The error bars are defined as s.d. (c) Transmission spectrum of a $\mathrm{Co}_{3} \mathrm{O}_{4} @ \mathrm{CoO}_{\mathrm{SC}}$ electrode at a loading amount of $25 \mu \mathrm{g} \mathrm{cm}{ }^{-2}$. Inset: digital photographs of $\mathrm{CO}_{3} \mathrm{O}_{4} @ \mathrm{CoO} \mathrm{SC}$ electrode. (d) Polarization curves for the OER of $\mathrm{Co}_{3} \mathrm{O}_{4} @ \mathrm{CoO}$ single-crystal nanocubes prepared using various reductant $\left(\mathrm{NaBH}_{4}\right)$ concentrations in $\mathrm{O}_{2}$-saturated $\mathrm{KOH}(0.5 \mathrm{M} ; \mathrm{pH} \sim 13.6)$ and at a $10 \mathrm{mVs}^{-1}$ scan rate. (e) Steadystate Tafel (overpotential versus log current) measurements of $\mathrm{Co}_{3} \mathrm{O}_{4} @ \mathrm{CoO}$ single-crystal nanocubes in alkaline and neutral conditions, commercial RuO ${ }_{2}$ catalysts $(0.5 \mathrm{M} \mathrm{KOH} ; \mathrm{pH} \sim 13.6)$, and $\mathrm{IrO}_{2}$ catalysts $(0.5 \mathrm{M} \mathrm{KOH} ; \mathrm{pH} \sim 13.6)$. All measurements were performed using RDE voltammetry upon a GC disk in desired electrolyte. Each data point represents the average of ten individual electrode samples where the error bars are defined as s.d. (f) Comparison of the $\mathrm{O}_{2}$ gas evolution and the charge throughout the circuit (line) in various current densities where the error bar are defined as s.d., indicating that the Faradaic efficiency of water oxidation was close to $100 \%$ with no substantial loss.

in situ X-ray absorption in a liquid environment in low throughput current (below $+1.7 \mathrm{~V}$ versus $\mathrm{RHE}$ ) by using the setup shown in Supplementary Fig. 3, and the extended X-ray absorption fine structure spectra of $\mathrm{Co}_{3} \mathrm{O}_{4} @ \mathrm{CoO}$ SCs were depicted in Fig. 2 d. We attributed the first peak at $\sim 1.5 \AA$ and the second and third peaks at $\sim 2.5$ and $3.1 \AA$, respectively, to the single scattering paths of the closest oxygen (that is, $\mathrm{Co}-\mathrm{O}$ ) and the second/third neighbouring cobalt metals (that is, Co-Co) surrounding the absorbing $\mathrm{Co}$ atoms. The $\mathrm{Co}-\mathrm{O}$ distance $(\sim 1.5 \AA)$ was typical for a $\mathrm{Co}_{3} \mathrm{O}_{4}$ normal spinel-type structure, and the first $\mathrm{Co}-\mathrm{Co}$ distance $(2.5 \AA)$ was typical for a Co (III)-Co bond with octahedrally coordinated Co atoms in a normal spinel structure. The second distance of $3.1 \AA$ was attributed to Co (II)Co bonds with tetrahedrally coordinated Co atoms. These results were consistent with the results determined for the spinel structure of $\mathrm{Co}_{3} \mathrm{O}_{4}$. Notably, a new peak was observed at $\sim 3.8 \AA$ when a higher potential of $+1.7 \mathrm{~V}$ (versus $\mathrm{RHE}$ ) was applied to a $\mathrm{Co}_{3} \mathrm{O}_{4} @ \mathrm{CoO} \mathrm{SC}$ electrode. The peak was attributed to the formation of cobalt oxyhydroxide phase on the surface of the $\mathrm{Co}_{3} \mathrm{O}_{4}$ SC thus led to a new scattering path of $\mathrm{Co}-\mathrm{O}$ from the cobalt oxyhydroxide phase, which was consistent with the results from X-ray photoelectron spectroscopy (Fig. 2e) and further confirmed the observation in our X-ray diffraction experiments. It was noted that the $\mathrm{CoOOH}$ layer formed from $\mathrm{Co}_{3} \mathrm{O}_{4}$ nanocubes without covering of $\mathrm{CoO}$ skin was characteristic of rough nature. Unlike $\mathrm{Co}_{3} \mathrm{O}_{4}$ nanocubes, the $\mathrm{CoOOH}$ layer formed from
$\mathrm{Co}_{3} \mathrm{O}_{4}$ nanocubes with covering of $\mathrm{CoO}$ skin exhibited a continuous and uniform surface. This observation can be attributed to the presence of $\mathrm{CoO}$ skin layer, while directly anodizing of $\mathrm{Co}$ ions on $\mathrm{Co}_{3} \mathrm{O}_{4}$ nanocubes surface resulted in a remarkably rough layer (Supplementary Fig. 4). Using the voltage-dependent in situ $\mathrm{X}$-ray diffraction/absorption approach, we concluded that a strong correlation exists between $\mathrm{O}_{2}$ gas evolution and the active metal centres with oxyhydroxide phase. More importantly, this junction layer can reversibly adapt its structure to accommodate harsh condition/environment without breaking the underlying scaffold.

Electrochemical performance. We evaluated the electrochemical activity of the $\mathrm{Co}_{3} \mathrm{O}_{4} @ \mathrm{CoO}$ SCs during the OER in alkaline and neutral conditions while $\mathrm{IrO}_{2}$ (Supplementary Fig. 5) and $\mathrm{RuO}_{2}$ (Supplementary Fig. 6) catalysts were also tested as references (Fig. 3a). The ohmic potential drop loss caused by the solution resistance was corrected. Noted that the loading amount of the $\mathrm{Co}_{3} \mathrm{O}_{4} @ \mathrm{CoO}$ SCs was optimized to attain the optimal conditions ( $\sim 25 \mu \mathrm{g} \mathrm{cm}^{-2}$; Fig. $\left.3 \mathrm{~b}\right)$, in which the catalysts layer could provide a wide range of transparency in the visible region (Fig. $3 \mathrm{c}$ ). This could allow the development of an electrocatalytic system without inner-filter effects that led to the absorption of an excessive amount of incident light and hindered charge transfer across the semiconductor/electrolyte interface ${ }^{37}$. Both $\mathrm{RuO}_{2}$ 


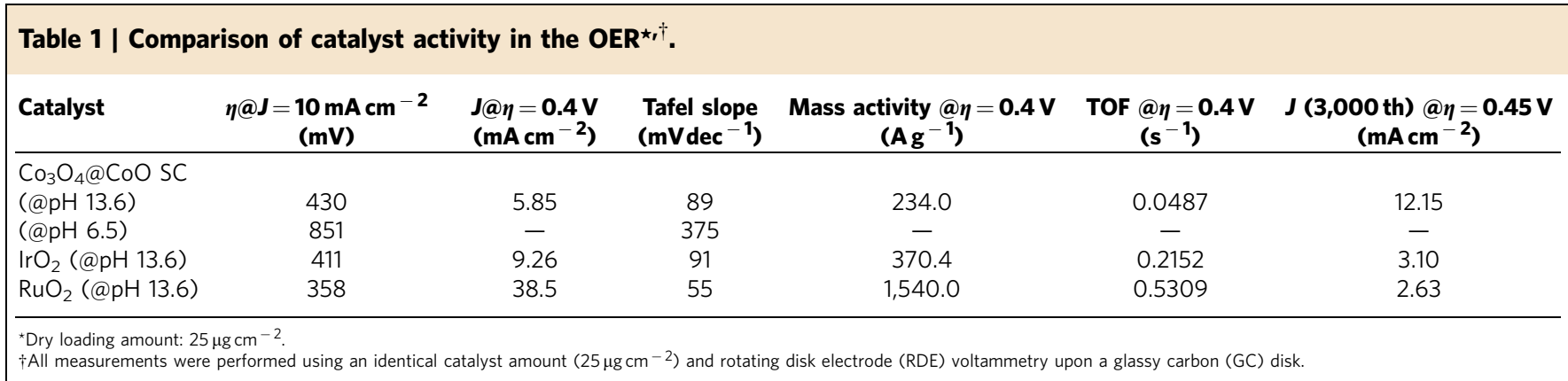

and $\mathrm{IrO}_{2}$ catalysts exhibited slightly lower onset potentials $(1.56 \mathrm{~V}$ versus RHE@ $5 \mathrm{~mA} \mathrm{~cm}^{-2}$ and $1.61 \mathrm{~V}$ versus RHE@ $5 \mathrm{~mA} \mathrm{~cm}^{-2}$ ) as compared with that of $\mathrm{Co}_{3} \mathrm{O}_{4} @ \mathrm{CoO}$ SCs, presumably because of the intrinsic nature of $\mathrm{RuO}_{2}$ and $\mathrm{IrO}_{2}$ catalysts ${ }^{18,19,38}$. Furthermore, the $\mathrm{Co}_{3} \mathrm{O}_{4} @ \mathrm{CoO} \mathrm{SC}$ could be operated in a neutral environment as well, except the OER onset potential observed shifted towards a higher voltage. This was attributed to the formation of more active phase on the surface of the $\mathrm{Co}_{3} \mathrm{O}_{4} @ \mathrm{CoO}$ SC in the alkaline condition and was consistent with theoretical and experimental Pourbaix diagrams ${ }^{31,33}$. It was noted that the thickness of the $\mathrm{CoO}$ layer should be tuned to achieve optimal condition since the usage of a larger amount of reductant led to some undesired reactions on $\mathrm{Co}_{3} \mathrm{O}_{4} \mathrm{SC}$ instead of further increasing thickness of $\mathrm{CoO}$ layer and resulted in a negative effect in their electrochemical performance (Fig. 3d).

The steady-state Tafel measurements of $\mathrm{Co}_{3} \mathrm{O}_{4} @ \mathrm{CoO} \mathrm{SC}, \mathrm{IrO}_{2}$ and $\mathrm{RuO}_{2}$ were shown in Fig. $3 \mathrm{e}$ and Table 1. The overpotential $(\eta)$ comparison of various electrocatalysts to reach a current density of $10 \mathrm{~mA} \mathrm{~cm}^{-2}$ was promising because this value was the approximate current density necessary for $10 \%$ efficient solar-tofuel conversion ${ }^{19,39}$. The $\mathrm{Co}_{3} \mathrm{O}_{4} @ \mathrm{CoO} \mathrm{SC}$ in alkaline condition yielded a current density of $10 \mathrm{~mA} \mathrm{~cm}^{-2}$ at a low overpotential of $0.430 \mathrm{~V}$, which was similar to the $\eta$ requirement for $\mathrm{IrO}_{2}$ $(0.411 \mathrm{~V})$ and $\mathrm{RuO}_{2}(0.358 \mathrm{~V})$ identified both in the present study and relevant literatures ${ }^{18,19}$. The Tafel slopes of $\mathrm{Co}_{3} \mathrm{O}_{4} @ \mathrm{CoO}$ SC were unable to achieve the lowest value that compared with those of other $3 d$-transition metal oxide systems ${ }^{18-20,26}$. We remarked that a low electrocatalyst loading amount $\left(25 \mu \mathrm{g} \mathrm{cm}^{-2}\right)$ was employed here, so that the catalysts can potentially be used in a photoelectrochemical system. Because of the low loading of electrocatalysts, the mass activity and the turnover frequency (TOF) calculated using these data achieved a mass activity of $\sim 234.0 \mathrm{Ag}^{-1}$ at $\eta=0.4 \mathrm{~V}$, which is equivalent to a TOF of $\sim 0.0487 \mathrm{~s}^{-1}$; this value is higher than that of other cobalt-based oxide systems to which high loading amounts were applied (approximately $\mathrm{mg} \mathrm{cm}^{-2}$ ), despite that these values were determined in slightly dissimilar conditions and were not directly comparable $11,18,40,41$. Comparing the quantities of gases produced and the amount of charge that passed through the circuit revealed that the $\mathrm{Co}_{3} \mathrm{O}_{4} @ \mathrm{CoO}$ SCs exhibited nearly $100 \%$ charge-to-chemical Faradic efficiency during $10 \mathrm{~h}$ in various current densities, indicating that these electrocatalysts could enable efficient carrier transportation without noticeable energy loss (Fig. 3f).

Stability studies of single-crystal electrocatalysts. Prolonged testing of the optimized $\mathrm{Co}_{3} \mathrm{O}_{4} @ \mathrm{CoO}$ SCs at a current density of $8 \mathrm{~mA} \mathrm{~cm}^{-2}$ was performed to maintain a constant current density for longer than $1,000 \mathrm{~h}$ ( $>40$ days; Fig. 4a and Supplementary Movie 1) without noticeable decay in the current or detaching from the substrate (measured using SEM; Supplementary Figs 7,8 and 9). In contrast, the $\mathrm{Co}_{3} \mathrm{O}_{4} \mathrm{SCs}$ was unable to achieve a stable current output, showing a remarkable decrease by $55 \%$ after $1,000 \mathrm{~h}$ of operation. This result suggested that the reliability of the $\mathrm{Co}_{3} \mathrm{O}_{4} @ \mathrm{CoO} \mathrm{SC}$ catalyst was superior to all previously reported systems; even after $1,000 \mathrm{~h}$ of operation, gas bubbles still emanated from the electrode surface (Supplementary Movie 1). To further test the long-term stability, we subjected it to a continual potential cycling between 1.0 and $2.0 \mathrm{~V}$ (versus RHE) and used the $\mathrm{IrO}_{2}$ and $\mathrm{RuO}_{2}$ catalysts as controls in $\mathrm{O}_{2}$-saturated $0.5 \mathrm{M} \mathrm{KOH}$ while all measurements were performed using rotating disk electrode (RDE) voltammetry upon a glassy carbon (GC) disk in the desired electrolyte. The conditions in the test were severe upon OER, because the potential was alternately applied, and the structure of the catalyst could be damaged by the continual valence cycling. Nevertheless, after 3,000 cycles of measurement, the $\mathrm{Co}_{3} \mathrm{O}_{4} @ \mathrm{CoO}$ SCs exhibited no significant decay in its activity, unlike the $\mathrm{IrO}_{2}$ and $\mathrm{RuO}_{2}$ catalysts, which exhibited rapid decay in performance and decreased to a negligible level $\left(3.1\right.$ and $2.6 \mathrm{~mA} \mathrm{~cm}^{-2}$ for $\mathrm{IrO}_{2}$ and $\mathrm{RuO}_{2}$ at $1.68 \mathrm{~V}$ versus $\mathrm{RHE}$, respectively) at the 3,000 th scan (Fig. $4 \mathrm{~b}$ ). The bare $\mathrm{Co}_{3} \mathrm{O}_{4} \mathrm{SCs}$ could only retain $54 \%$ of the initial current density after 6,000 scans (at $1.78 \mathrm{~V}$ versus $\mathrm{RHE}$ ) while the activity of $\mathrm{Co}_{3} \mathrm{O}_{4} @ \mathrm{CoO}$ SCs did not show noticeable decay. Our results suggested that incorporation of a reversible adapting layer covering nanocrystal electrocatalyst could become an effective design strategy for improving the reliability of electrocatalysts. The spinel type is the most stable phase in Co-based system ${ }^{18,31}$, and it is able to transform into active oxyhydroxide phase as well. Unlike spinel-type $\mathrm{Co}_{3} \mathrm{O}_{4}$, a rock salt $\mathrm{CoO}$ layer is kinetically more facile to achieve the structural transformation into active oxyhydroxide phase in surface metal centres. This was indicative that the linear sweep voltammetry curve of the $\mathrm{Co}_{3} \mathrm{O}_{4} @ \mathrm{CoO}$ SCs electrode exhibited a considerably lower OER onset potential and higher current density compared with those of the bare $\mathrm{Co}_{3} \mathrm{O}_{4} \mathrm{SC}$ electrode (Fig. 3d).

\section{Discussion}

Clearly, the employment of rock salt CoO layer can mediate the interface of electrolyte/electrocatalysts and play multiple roles for efficiently catalyzing the oxidation of water. First, the surface $\mathrm{CoO}$ layer is kinetically facile to reach the active oxyhydroxide phase in active metal centres and serve as the active skin for OER. Active metal centres with oxyhydroxide phases are formed in situ with lower overpotential to facilitate efficient oxygen evolution reactions. Second, the $\mathrm{CoO}$ film provided an excellent protection to $\mathrm{Co}_{3} \mathrm{O}_{4}$ single-crystal nanocubes, because the volume change from Co anodization can be buffered by the $\mathrm{CoO}$ layer to avoid mechanical damage to the underlay $\mathrm{Co}_{3} \mathrm{O}_{4}$ scaffolds. The $\mathrm{Co}_{3} \mathrm{O}_{4}$ nanocubes $\left(\sim 22 \AA^{3}\right.$ per Co) need to undergo a drastic volume change in order to transform into the active metal oxyhydroxides. However, the phase transformations from $\mathrm{Co}_{3} \mathrm{O}_{4}$ to $\beta$-CoOOH $\left(\sim 30 \AA^{3}\right.$ per Co) and/or $\alpha$-CoOOH $\left(\sim 29 \AA^{3}\right.$ per Co $)$ caused drastic volume expansions of approximately 36 and $32 \%$, 

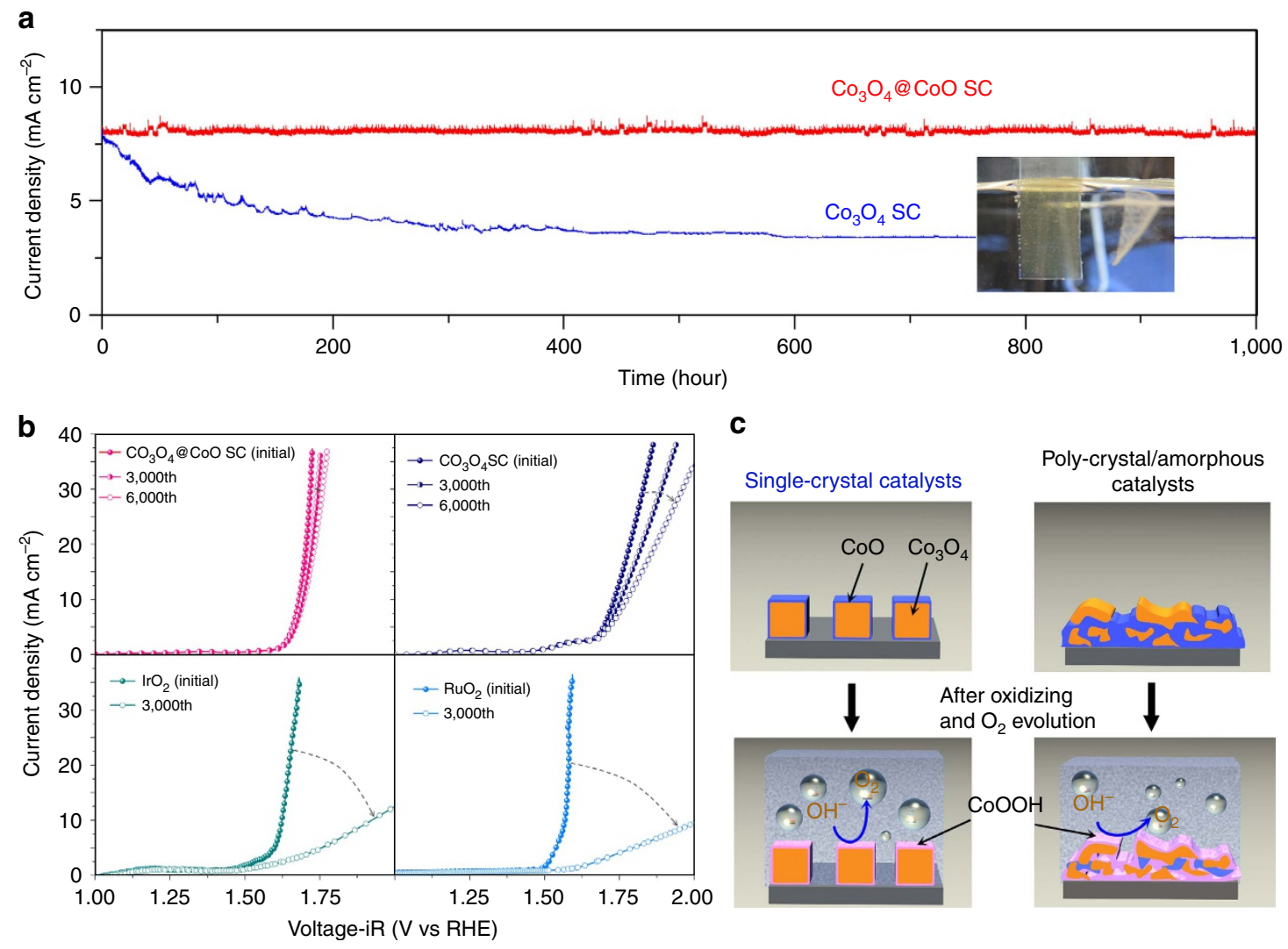

Figure 4 | Stability test. (a) Current versus time data on a $\mathrm{Co}_{3} \mathrm{O}_{4} @ \mathrm{CoO} \mathrm{SC}$ electrode and $\mathrm{Co}_{3} \mathrm{O}_{4} \mathrm{SC}$ electrode in $0.5 \mathrm{M} \mathrm{KOH}(\mathrm{pH}=13.6)$ for $1,000 \mathrm{~h}$ ( $>40$ days) at a constant potential of $1.85 \mathrm{~V}$ (versus $\mathrm{RHE}$ ), in which no significant current throughput decay was observed as compared to $\mathrm{Co}_{3} \mathrm{O}_{4} \mathrm{SC}$ electrode. (b) OER polarization curves of $\mathrm{Co}_{3} \mathrm{O}_{4} @ \mathrm{CoO} \mathrm{SC}, \mathrm{Co}_{3} \mathrm{O}_{4} \mathrm{SC}, \mathrm{IrO}_{2}$, and $\mathrm{RuO}_{2}$ catalysts subjected to continual potential cycling between 1.0 and $2.0 \mathrm{~V}$ (versus $\mathrm{RHE}$ ) in $\mathrm{O}_{2}$-saturated $\mathrm{KOH}\left(0.5 \mathrm{M}\right.$ ) for 3,000 (and 6,000) cycle measurements; the $\mathrm{Co}_{3} \mathrm{O}_{4} @ \mathrm{CoO}$ SC retained activity, unlike the IrO $\mathrm{S}_{2}$ and $\mathrm{RuO}_{2}$ control catalysts, which failed to achieve the initial current density. All measurements were performed using rotating disk electrode (RDE) voltammetry upon a glassy carbon (GC) disk in desired electrolyte. (c) Schematic representation of structural transformation within single-crystal and amorphous/polycrystal electrocatalysts, indicating that the formation of more active/oxidized phases may generate structural stress and/or voids and weaken the stability of materials. The $\mathrm{CoO}$ layer that eliminated the substantial volume change during the $\mathrm{OER}$ provided excellent protection for the $\mathrm{Co}_{3} \mathrm{O}_{4}$ nanocubes.

respectively. Therefore, the surface $\mathrm{CoO}$ layer can effectively buffer the harsh structural variations without damaging the $\mathrm{Co}_{3} \mathrm{O}_{4}$ scaffold. Third, single-crystal $\mathrm{Co}_{3} \mathrm{O}_{4}$ nanocubes are characteristically defect free in nature, and thus they avoid selfoxidizing and offer a robust scaffold without energetic losses. In contrast, in the case of amorphous/polycrystal, the formation of more active/oxidized phases are launched from grain boundaries and/or the structural defects, which invariably generates structural stress and/or voids. On the contrary, the volume expansion/contraction did not harm the scaffold $\left(\mathrm{Co}_{3} \mathrm{O}_{4}\right)$ of electrocatalyst owing to the presence of the $\mathrm{CoO}$ layer (Fig. 4c). This strategy significantly improves the reliability of an electrocatalyst through the employment of a reversible adapting junction, and should be generalized and is potentially applicable to various electrocatalysis systems. The main guidelines are that this junction should be able to produce the catalytic metal centre with active phase, withstand the volume change from reaction and mediate the interface of catalyst/electrolyte.

In conclusion, the developed single-crystal $\mathrm{Co}_{3} \mathrm{O}_{4}$ nanocube catalysts with reversible adapting $\mathrm{CoO}$ skin layers are reliable, composed of common earth materials, environmental friendly and can be used as efficient water oxidation catalysts that can be incorporated into electrochemical/photoelectrochemical systems. An in situ X-ray diffraction method was used to identify a strong correlation between the $\mathrm{O}_{2}$ gas evolution and the formation of active metal centres with a metal oxyhydroxide phase through skin layer in liquid condition, and further revealed that this skin layer could remarkably protect underlay electrocatalysts through reversible transformation to active phases. Thus, reversible adapting $\mathrm{CoO}$ skin layers and single-crystal $\mathrm{Co}_{3} \mathrm{O}_{4}$ nanocubes play complementary roles to achieve an active and robust electrocatalyst, and lead to retaining a stable current for $>1,000 \mathrm{~h}$ without exhibiting noticeable decay. These results provided significant progress towards the understanding of the phase of active metal centres on the electrocatalysts, and the advance of the reliability of OER electrocatalysts. This in situ $\mathrm{X}$-ray technique provides a powerful tool to the investigation of the phase of surface active metal centre in electrocatalysis and potentially can be applied in probing other catalysis systems. In practical application, solar water splitting or artificial photosynthesis device can be achieved through integration of a reliable catalytic system with photovoltaic solar cell, which captures light energy to generate sufficient driving force for $\mathrm{H}_{2} / \mathrm{O}_{2}$ generation. For instance, Luo et al. ${ }^{42}$ recently demonstrated a perovskite tandem solar cell with incorporation of metal layered double hydroxide catalyst to realize a solar-to-hydrogen efficiency of $12.3 \%$ for water photolysis. The remarks described here can serve as a new strategy to design robust electrocatalysts for artificial photosynthesis/water photolysis that allows for the conversion of sunlight into $\mathrm{O}_{2}$ and chemical fuels, where low catalyst loading is 
essential for the photoelectrochemical system. Although a cobalt-based material was used as a platform to examine the single-crystal electrocatalysts in this study, the performance of the single Co compounds can be greatly optimized by further incorporating other functional materials. Our strategy here provided a fundamentally design of promising electrocatalysts and should become an accepted technique for electrochemical/ photoelectrochemical systems.

\section{Methods}

Materials. Sodium borohydrate $\left(\mathrm{NaBH}_{4}\right)$ and sodium nitrate $\left(\mathrm{NaNO}_{3}\right)$ were purchased from Acros Organics. Cobalt nitrate hexahydrate, potassium hydroxide and sodium sulfate were obtained from Sigma-Aldrich. Sodium hydroxide was purchased from Fluka. All chemicals were used without further purification. The water used throughout this investigation was reagent-grade water produced using an ELGA ultrapure-water purification system $(18.2 \mathrm{M} \Omega \mathrm{cm})$.

Preparation of single-crystal $\mathbf{C o}_{3} \mathbf{O}_{\mathbf{4}} @ \mathbf{C o O}$ nanocubes. To synthesize the $\mathrm{Co}_{3} \mathrm{O}_{4}$ nanocubes, $\mathrm{NaNO}_{3}(45.0 \mathrm{~g})$ was dissolved in an aqueous solution of $0.3 \mathrm{M} \mathrm{NaOH}$ $(100 \mathrm{ml})$ in a 3-necked round bottom flask at $100^{\circ} \mathrm{C}$ and stirred vigorously while the temperature was maintained for $5 \mathrm{~min}$. After the mixture was stirred for $5 \mathrm{~min}$, an aqueous solution containing $1.0 \mathrm{M} \mathrm{Co}\left(\mathrm{NO}_{3}\right)_{2}(20 \mathrm{ml})$ was quickly added to the flask and heated to $115^{\circ} \mathrm{C}$ in purified air $\left(50 \mathrm{ml} \mathrm{min}^{-1}\right)$. The colour of the precipitate slowly changed from purple to brown and finally to black after being heated for $12 \mathrm{~h}$. The resulting black colloid $\left(\mathrm{Co}_{3} \mathrm{O}_{4}\right.$ single-crystal nanocubes) was centrifuged at 7,000 r.p.m. and then washed several times with $\mathrm{HCl}(1.0 \mathrm{M})$ and deionized water. To prepare the thin $\mathrm{CoO}$ layer on the surface of the as-prepared $\mathrm{Co}_{3} \mathrm{O}_{4}$ single-crystal nanocubes, $300 \mu \mathrm{l}$ of the $\mathrm{Co}_{3} \mathrm{O}_{4}$ nanocube colloid $\left(0.19 \mathrm{gl}^{-1}\right)$ was reacted with a desired concentration (1.50-40.5 mM) of a $\mathrm{NaBH}_{4}$ aqueous solution $(20 \mathrm{ml})$ during magnetic stirring at room temperature. After $20 \mathrm{~min}$, the solid product was washed several times, separated from the solution through centrifugation and then dried.

Characterization. The morphology of the specimens was studied by employing TEM using a JEOL JEM-2100F microscope that was operated at $200 \mathrm{kV}$, a Hitachi $\mathrm{H}-7650$ that was operated at $120 \mathrm{kV}$, and a JEOL JSM-7600F field emission scanning electron microscope. The specimens were obtained by placing several drops of the colloidal solution onto a Formvar-covered copper grid and evaporating them in air at room temperature. The chemical composition analysis of the single-crystal nanocubes was performed using an energy-dispersive X-ray analysis (EDX) line scan and EELS in a JEOL JEM-2100F FE-TEM that was equipped with an energy-dispersive spectroscopy probe. The loading amounts were determined using an inductively coupled plasma-mass spectrometer (Agilent $7700 \mathrm{e}$ ). The crystallographic structures of the nanocubes were analysed by employing X-ray powder diffraction by using an X'Pert Pro diffractometer with $\mathrm{Cu} \mathrm{K} \alpha$ radiation ( $\lambda=1.5418 \AA$ ). Real-time oxygen gas evolution was measured by a Gas chromatography (Agilent 7890B) with thermal conductivity detector. The absorption spectra of the $\mathrm{Co}_{3} \mathrm{O}_{4}$ electrodes were measured using a UV-visible/near-infrared Spectrophotometer V670 (JASCO International Co., Ltd) with an integrating sphere. X-ray absorption measurements of the synthesized samples were performed using synchrotron radiation at room temperature with a handmade reaction cell that was designed for this in situ measurement. Measurements were performed at the Co K-edge $(7,709 \mathrm{eV})$ by using the sample, which was maintained at room temperature, and the $01 \mathrm{C} 1$ beamline at the National Synchrotron Radiation Research Center (NSRRC), Taiwan designed for these experiments. X-ray absorption data were analysed according to standard procedures, including pre-edge and post-edge background subtraction, normalization with respect to edge height, and Fourier transformation. X-ray diffraction measurements were conducted using a handmade reaction cell that was designed for this in situ measurement; all spectra were collected using the 01C2 beamline at the NSRRC, which had a radiation light source of $12 \mathrm{keV}$. It was worth noting that closer examination of the catalysts by using X-ray absorption approach was difficult, because gas bubbles were quickly generated from the increasing applied potential, and thus smooth oscillation cannot be achieved through absorption manner.

In situ grazing-angle $\mathrm{X}$-ray diffraction studies. The grazing incident $\mathrm{X}$-ray diffraction of thin film samples were performed at the BL01C2 beamline of the NSRRC in Taiwan, in which the ring of NSRRC was operated at energy $1.5 \mathrm{GeV}$ with a typical current $\sim 360 \mathrm{~mA}$. Two pairs of slits and one collimator were set up in experimental hutch to provide a collimated beam with dimensions of typical $0.5 \times 0.5 \mathrm{~mm}(\mathrm{H} \times \mathrm{V})$ at the sample position. An incident angle about $0.2^{\circ}$ was employed in present study, in which the X-ray irradiation can pass through several thousand Angstroms upon surface of sample. This geometry allows us to significantly enhance the X-ray scattering intensity from the surface of sample. The grazing-angle was optimized to probe the interior of the sample surface and achieved the best $S / N$ ratio for maximizing scattering signal from electrode surface. In present study, the wavelength of the incident X-rays was $1.033210 \AA(12 \mathrm{keV})$ delivered from the $5 \mathrm{~T}$ Superconducting Wavelength Shifter and a Si (111) triangular crystal monochromator, which allowed to achieve an optimized condition for distinguishing scattering rings. The diffraction pattern was recorded with a Mar345 imaging plate detector which was located $\sim 320 \mathrm{~mm}$ behind the sample, while the pixel size of image was $100 \mathrm{~m}$ with typical exposure duration of $1 \mathrm{~min}$. To achieve a correct condition, the diffraction angles were calibrated according to Bragg positions of $\mathrm{CeO}_{2}$ (SRM 674b) standards in desired geometry, and then a program of GSAS II was employed to obtain corresponding one-dimensional powder diffraction profile with cake-type integration. In terms of liquid cell, a kapton polyimide film (DuPont) with a thickness of $0.06 \mathrm{~mm}$ served as $\mathrm{X}$-ray window in liquid cell which was mode of Teflon line and the thickness of electrolyte below $1 \mathrm{~mm}$ was preciously controlled to suppress the interference from liquid electrode.

Electrochemical studies. To achieve fair comparison among all samples and well control the geometric area/impedance loss, all measurements were performed at room temperature by using RDE voltammetry upon a GC disk at 1,600 r.p.m., in which rotating disk working electrode made of glassy carbon (GC electrode, $5 \mathrm{~mm}$ in diameter, PINE:AFE3T050GC PINE, area: $0.196 \mathrm{~cm}^{2}$ ) connected to a CHI-704E bipotentiostat (CHI Instruments). Uniformly dispersed electrocatalyst slurry was obtained via an ultrasonic dispersal of electrocatalysts in deionized water. In the case of working electrodes of glassy carbon, the GC electrode was initially polished using $0.05 \mu \mathrm{m}$ alumina powder, and then $15 \mu \mathrm{l}$ of the electrocatalyst slurry was placed on the working electrode, which was dried in air at $40^{\circ} \mathrm{C}$ Finally, the catalyst-loaded GC electrode was covered with $20 \mu \mathrm{l}$ of a $1 \%$ Nafion solution diluted using isopropyl alcohol and dried in a nitrogen atmosphere. Before the electrochemical measurement, the electrolyte was degassed by bubbling oxygen for at least $30 \mathrm{~min}$ to achieve a saturation condition of oxygen gas. In terms of in situ experiments, electrodes were prepared by incorporating as-synthesized nanocubes within a well-defined area $\left(2 \times 1 \mathrm{~cm}^{2}\right)$ onto a fluorine-doped tin oxide-coated glass (CP-Solar, Tec 7) since GC disk is unable to utilize in such experiments, which was washed using acetone, isopropanol and deionized water before use; the nanocube film electrodes were subsequently annealed at $175^{\circ} \mathrm{C}$ for $4 \mathrm{~h}$. Electrochemical experiments were performed in a typical three-electrode system controlled using a CHI-704E or CHI-405A potentiostat (CHI Instruments). Linear sweep voltammetry was performed at a scan rate of $100 \mathrm{mV} \mathrm{s}^{-1}$. All potentials were referenced to an $\mathrm{Hg} / \mathrm{HgO}$ reference electrode or $\mathrm{Ag} / \mathrm{AgCl}$ reference electrode, and $\mathrm{Pt}$ was used as the counter electrode in all measurements, in which the electrolyte was either a $0.5 \mathrm{M} \mathrm{Na}_{2} \mathrm{SO}_{4}(\mathrm{pH} \sim 6.5)$ solution or a $0.5 \mathrm{M} \mathrm{KOH}$ ( $\mathrm{pH} \sim 13.6)$ solution. All potentials were adjusted to compensate for the ohmic potential drop losses $\left(R_{\mathrm{u}}\right)$ that arose from the solution resistance and calibrated with respect to RHE.

$$
E_{\mathrm{RHE}}=E_{\mathrm{ref}}+0.05916 \mathrm{pH}-i \times R_{\mathrm{u}}
$$

A long-term amperometric $i-t$ curve was performed using a sampling interval of $1 \mathrm{~s}$, and each run time was $86,400 \mathrm{~s}(24 \mathrm{~h})$. Regarding the $1,000-\mathrm{h} \mathrm{O}_{2}$ evolution, the number of repetitive runs was 42 to ensure that measurement was conducted for $1,000 \mathrm{~h}$. The volume of the electrolyte was kept constant to maintain a constant immersed-area of electrodes.

The values of mass activity $\left(\mathrm{Ag}^{-1}\right)$ were calculated using the following equation:

$$
\text { Mass activity }\left(\mathrm{Ag}^{-1}\right)=J / M
$$

where $M$ is the electrocatalyst loading amount $\left(25 \mu \mathrm{g} \mathrm{cm}^{-2}\right)$ and $J$ is the measured current density $\left(\mathrm{mA} \mathrm{cm}^{-2}\right)$.

The values of TOF were calculated by assuming that every metal atom was involved in the catalysis (lower limits):

$$
\mathrm{TOF}=\frac{J}{4 \times F \times n}
$$

where $J$ is the current density $\left(\mathrm{A} \mathrm{cm}^{-2}\right), F$ is Faraday's constant $\left(96485.3 \mathrm{C} \mathrm{mol}^{-1}\right)$ and $n$ is moles of electrocatalysts $\left(\mathrm{mol} \mathrm{cm}^{-2}\right)$.

\section{References}

1. Dresselhaus, M. S. \& Thomas, I. L. Alternative energy technologies. Nature 414, 332-337 (2001).

2. Gasteiger, H. A. \& Markovic, N. M. Just a dream-or future reality? Science 324, 48-49 (2009).

3. Lefevre, M., Proietti, E., Jaouen, F. \& Dodelet, J.-P. Iron-based catalysts with improved oxygen reduction activity in polymer electrolyte fuel cells. Science 324, 71-74 (2009).

4. Hammarstrom, L. \& Hammes-Schiffer, S. Artificial photosynthesis and solar fuels. Acc. Chem. Res. 42, 1859-1860 (2009).

5. Khan, S. U. M., Al-Shahry, M. \& Ingler, W. B. Efficient photochemical water splitting by a chemically modified $n-\mathrm{TiO}_{2}$. Science 297, 2243-2245 (2002).

6. Nocera, D. G. The artificial leaf. Acc. Chem. Res. 45, 767-776 (2012).

7. Kudo, A. \& Miseki, Y. Heterogeneous photocatalyst materials for water splitting. Chem. Soc. Rev. 38, 253-278 (2009).

8. Schlapbach, L. \& Zuttel, A. Hydrogen-storage materials for mobile applications. Nature 414, 353-358 (2001). 
9. McAlpin, J. G., Stich, T. A., Casey, W. H. \& Britt, R. D. Comparison of cobalt and manganese in the chemistry of water oxidation. Coord. Chem. Rev. 256, 2445-2452 (2012).

10. Suntivich, J., May, K. J., Gasteiger, H. A., Goodenough, J. B. \& Shao-Horn, Y. A perovskite oxide optimized for oxygen evolution catalysis from molecular orbital principles. Science 334, 1383-1385 (2011).

11. Yeo, B. S. \& Bell, A. T. Enhanced activity of gold-supported cobalt oxide for the electrochemical evolution of oxygen. J. Am. Chem. Soc. 133, 5587-5593 (2011).

12. Gorlin, Y. et al. In situ x-ray absorption spectroscopy investigation of a bifunctional manganese oxide catalyst with high activity for electrochemical water oxidation and oxygen reduction. J. Am. Chem. Soc. 135, 8525-8534 (2013).

13. Jiao, F. \& Frei, H. Nanostructured cobalt oxide clusters in mesoporous silica as efficient oxygen-evolving catalysts. Angew. Chem. Int. Ed. 48, 1841-1844 (2009).

14. Kenney, M. J. et al. High-performance silicon photoanodes passivated with ultrathin nickel films for water oxidation. Science 342, 836-840 (2013).

15. Chen, Y. W. et al. Atomic layer-deposited tunnel oxide stabilizes silicon photoanodes for water oxidation. Nat. Mater. 10, 539-544 (2011).

16. Smith, R. D. L. et al. Photochemical route for accessing amorphous metal oxide materials for water oxidation catalysis. Science 340, 60-63 (2013).

17. Li, Y., Hasin, P. \& Wu, Y. $\mathrm{Ni}_{x} \mathrm{Co}_{3-x} \mathrm{O}_{4}$ nanowire arrays for electrocatalytic oxygen evolution. Adv. Mater. 22, 1926-1929 (2010).

18. Trotochaud, L., Ranney, J. K., Williams, K. N. \& Boettcher, S. W. Solution-cast metal oxide thin film electrocatalysts for oxygen evolution. J. Am. Chem. Soc. 134, 17253-17261 (2012).

19. McCrory, C. C. L., Jung, S., Peters, J. C. \& Jaramillo, T. F. Benchmarking heterogeneous electrocatalysts for the oxygen evolution reaction. J. Am. Chem. Soc. 135, 16977-16987 (2013).

20. Smith, R. D. L., Prevot, M. S., Fagan, R. D., Trudel, S. \& Berlinguette, C. P. Water Oxidation catalysis: electrocatalytic response to metal stoichiometry in amorphous metal oxide films containing iron, cobalt, and nickel. J. Am. Chem. Soc. 135, 11580-11586 (2013).

21. Kanan, M. W. \& Nocera, D. G. In situ formation of an oxygen-evolving catalyst in neutral water containing phosphate and $\mathrm{Co}^{2+}$. Science 321, 1072-1075 (2008).

22. Kanan, M. W. et al. Structure and valency of a cobalt-phosphate water oxidation catalyst determined by in situ X-ray spectroscopy. J. Am. Chem. Soc. 132, 13692-13701 (2010).

23. Subbaraman, R. et al. Trends in activity for the water electrolyser reactions on 3d M(Ni,Co,Fe,Mn) hydr(oxy)oxide catalysts. Nat. Mater. 11, 550-557 (2012).

24. Trotochaud, L., Young, S. L., Ranney, J. K. \& Boettcher, S. W. Nickel-iron oxyhydroxide oxygen-evolution electrocatalysts: the role of intentional and incidental iron incorporation. J. Am. Chem. Soc. 136, 6744-6753 (2014).

25. May, K. J. et al. Influence of oxygen evolution during water oxidation on the surface of perovskite oxide catalysts. J. Phys. Chem. Lett. 3, 3264-3270 (2012).

26. Yin, Q. et al. A fast soluble carbon-free molecular water oxidation catalyst based on abundant metals. Science 328, 342-345 (2010).

27. Hocking, R. K. et al. Water-oxidation catalysis by manganese in a geochemicallike cycle. Nat. Chem. 3, 461-466 (2011).

28. Gao, M.-R., Xu, Y.-F., Jiang, J., Zheng, Y.-R. \& Yu, S.-H. Water oxidation electrocatalyzed by an efficient $\mathrm{Mn}_{3} \mathrm{O}_{4} / \mathrm{CoSe}_{2}$ nanocomposite. J. Am. Chem. Soc. 134, 2930-2933 (2012).

29. Min-Rui Gao, X. C. et al. Nitrogen-doped graphene supported $\mathrm{CoSe}_{2}$ nanobelt composite catalyst for efficient water oxidation. ACS Nano 8, 3970-3978 (2014).

30. Man, I. C. et al. Universality in oxygen evolution electrocatalysis on oxide surfaces. Chemcatchem 3, 1159-1165 (2011)

31. Bajdich, M., Garcia-Mota, M., Vojvodic, A., Norskov, J. K. \& Bell, A. T. Theoretical investigation of the activity of cobalt oxides for the electrochemical oxidation of water. J. Am. Chem. Soc. 135, 13521-13530 (2013).

32. Zhang, M., de Respinis, M. \& Frei, H. Time-resolved observations of water oxidation intermediates on a cobalt oxide nanoparticle catalyst. Nat. Chem. 6, 362-367 (2014)
33. Hamdani, M., Singh, R. N. \& Chartier, P. $\mathrm{Co}_{3} \mathrm{O}_{4}$ and Co-based spinel oxides bifunctional oxygen electrodes. Int. J. Hydrogen Energy 5, 556-577 (2010).

34. Hochbaum, A. I. \& Yang, P. Semiconductor nanowires for energy conversion. Chem. Rev. 110, 527-546 (2010).

35. Villanueva-Cab, J., Jang, S. R., Halverson, A. F., Zhu, K. \& Frank, A. J. Trap-free transport in ordered and disordered $\mathrm{TiO}_{2}$ nanostructures. Nano Lett. 14, 2305-2309 (2014).

36. Wang, Z. L., Yin, J. S. \& Jiang, Y. D. EELS analysis of cation valence states and oxygen vacancies in magnetic oxides. Micron 31, 571-580 (2000).

37. Sun, Y. et al. Electrodeposited cobalt-sulfide catalyst for electrochemical and photoelectrochemical hydrogen generation from water. J. Am. Chem. Soc. 135, 17699-17702 (2013).

38. Stoerzinger, K. A., Qiao, L., Biegalski, M. D. \& Shao-Horn, Y. Orientation-dependent oxygen evolution activities of rutile $\mathrm{IrO}_{2}$ and $\mathrm{RuO}_{2}$. J. Phys. Chem. Lett. 5, 1636-1641 (2014).

39. Matsumoto, Y. \& Sato, E. Electrocatalytic properties of transition-metal oxides for oxygen evolution reaction. Mater. Chem. Phys. 14, 397-426 (1986).

40. Esswein, A. J., McMurdo, M. J., Ross, P. N., Bell, A. T. \& Tilley, T. D. Size-dependent activity of $\mathrm{Co}_{3} \mathrm{O}_{4}$ nanoparticle anodes for alkaline water electrolysis. J. Phys. Chem. C 113, 15068-15072 (2009).

41. Lee, Y., Suntivich, J., May, K. J., Perry, E. E. \& Shao-Horn, Y. Synthesis and activities of rutile $\mathrm{IrO}_{2}$ and $\mathrm{RuO}_{2}$ nanoparticles for oxygen evolution in acid and alkaline solutions. J. Phys. Chem. Lett. 3, 399-404 (2012).

42. Luo, J. et al. Water photolysis at $12.3 \%$ efficiency via perovskite photovoltaics and earth-abundant catalysts. Science 345, 1593-1596 (2014).

\section{Acknowledgements}

We acknowledge support from the Ministry of Science and Technology, Taiwan (Contracts Nos. MOST 102-2113-M-002-013-MY2, MOST 104-2113-M-213-001 and MOST 104-2113-M-002-011-MY2), and are grateful to Ms Chia Ying Chien and Su Jen Ji of the Ministry of Science and Technology (National Taiwan University) for their assistance during the TEM and scanning electron microscopy experiments.

\section{Author contributions}

C.W.T. performed the experiments and analysed the results; Y.-Y.H. and Y.Z. participated in the experiments and contributed to the in situ measurements; Y.P.S performed GC measurement; H.-S.S. and T.S.C. discussed some XRD and XAS results; Y.C.C. discussed the results; H.M.C. supervised the research, wrote the paper and discussed the results.

\section{Additional information}

Supplementary Information accompanies this paper at http://www.nature.com/ naturecommunications

Competing financial interests: The authors declare no competing financial interests.

Reprints and permission information is available online at http://npg.nature.com/ reprintsandpermissions/

How to cite this article: Tung, C.-W. et al. Reversible adapting layer produces robust single-crystal electrocatalyst for oxygen evolution. Nat. Commun. 6:8106 doi: $10.1038 /$ ncomms9106 (2015)

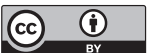

This work is licensed under a Creative Commons Attribution 4.0 International License. The images or other third party material in this article are included in the article's Creative Commons license, unless indicated otherwise in the credit line; if the material is not included under the Creative Commons license, users will need to obtain permission from the license holder to reproduce the material. To view a copy of this license, visit http://creativecommons.org/licenses/by/4.0/ 